\title{
Spatio-temporal variability of past accumulation rates inferred from isochronous layers at Dome A, East Antarctica
}

\author{
Tiantian WANG,${ }^{1,2}$ Bo SUN, ${ }^{2}$ Xueyuan $\mathrm{TANG}^{2}$ Xiaoping PANG, ${ }^{1}$ Xiangbin CUI, ${ }^{2}$ \\ Jingxue GUO, ${ }^{2}$ Hui WANG ${ }^{2}$ \\ ${ }^{1}$ Chinese Antarctic Center of Surveying and Mapping, Wuhan University, Wuhan, China \\ E-mail: wangtian890320@163.com \\ ${ }^{2}$ Polar Research Institute of China, Shanghai, China
}

\begin{abstract}
Studies of palaeo-accumulation rates at Dome A, East Antarctica, are entirely absent. Here, spatio-temporal variations in ice accumulation rates for the past $\sim 161$ ka are calculated from isochronous internal layering, traced from radio-echo sounding (RES) data collected by the Polar Research Institute of China (PRIC) during the 21st CHINARE. The layers are dated by linking them to the site of Vostok ice core along an RES profile, which was flown by the Alfred-Wegener-Institut (AWI) in the Dome Connection East Antarctica (DoCo) project. The Dansgaard-Johnsen model is used to determine the spatial and temporal pattern of ice accumulation in Dome A region. The results show that there is a slight increasing pattern of ice accumulation from south to north along the $216 \mathrm{~km}$ radar profile at Dome A. The lowest ice accumulation rates were calculated around the Dome A zone. In the past $\sim 90 \mathrm{ka}$, there were relatively high accumulation rates during the time period 34-47 ka (Marine Isotope Stage 3) at Dome A.
\end{abstract}

KEYWORDS: Dome A, isochrones, past accumulation rate, radio-echo sounding

\section{INTRODUCTION}

Extracting the record of past climate, simulating the evolution of ice sheets and ice-sheet mass balance all require data on accumulation rates (Petit and others, 1999; Lenaerts and others, 2012). Recent accumulation rates can be obtained in situ from stake readings (Ding and others, 2011), shallow cores (Oerter and others, 2000), or can be derived from satellite observations (Arthern and others, 2006). A more challenging task is estimating the palaeo-accumulation rate. Past accumulation rates can be evaluated from established chronologies at ice-core drilling sites. Drilling a deep ice core, however, is expensive and labor intensive, and data are spatially restricted. Radio-echo sounding (RES) surveys provide a good method to acquire spatially extensive accumulation rate data where no ice cores exist by continuous measurements of internal reflections within the ice sheet (Paren and others, 1975). Internal layers in ice are caused by (1) firn density variations in the upper part of the ice sheet, (2) crystal-orientation fabrics and (3) the presence of impurities such as volcanic ash, acids and sea salt (Corr and others, 1993; Fujita and others, 1999). These layers are believed to be isochronous surfaces (Millar and others, 1981). The depth of an isochronous layer contains information about two variables intimately linked to each other: the past accumulation rate and the age of the ice. If independent dating of a specific layer is carried out, the past accumulation rate can be inferred from a layer-thinning function.

One of the earliest models that describe the thinning of the annual layers at the summit of an ice sheet is the DansgaardJohnsen model (D-J model; Dansgaard and Johnsen, 1969). This model was successfully used by Dahl-Jensen and others (1993) and Fahnestock and others (2001) to reconstruct past accumulation rates from the sequences of dated layers for the Greenland ice sheet. In Antarctica, Siegert
(2003) used the D-J model to determine the spatial and temporal variation in East Antarctic ice accumulation over the Last Glacial cycle. Similarly, Leysinger-Vieli and others (2004) reconstructed the ice accumulation history for the region from Ridge $B$ to Vostok station. Huybrechts and others (2009) derived new strain-thinning functions from established chronologies and used internal ice layers to infer the spatio-temporal pattern of accumulation rate in Dronning Maud Land. Furthermore, these palaeo-accumulation rates were used to fine-tune the relation between accumulation rate and temperature. In addition to the above studies, the spatial variation of accumulation rate along a flowband can be also recovered from analysis of the shapes of internal layers by simulating a range of accumulation patterns with an ice flow model to calculate sets of internal layer patterns. Inverse techniques can then find which accumulation pattern reproduces the observed shape of internal layers from RES measurements (Nereson and others, 2000; Waddington and others, 2007; Hindmarsh and others, 2009; Macgregor and others, 2009; Leysinger-Vieli and others, 2011).

Dome A $\left(80^{\circ} 22^{\prime} 63^{\prime \prime} \mathrm{S}, 77^{\circ} 22^{\prime} 90^{\prime \prime} \mathrm{E}\right)$ is the highest plateau (4092.46 $\mathrm{m}$ a.s.l.) of the Antarctic ice sheet, and it has been identified as an important location to drill a deep ice core (Xiao and others, 2008; Sun and others, 2009, 2014; Zhang and others, 2014). There are several publications about recent accumulation rates at Dome $\mathrm{A}$ (Hou and others, 2007; Ding and others, 2011; Wang and others, 2013), but little is known of accumulation rates deeper in the past. Sun and others (2014) modeled the age of the ice beneath Dome A, and we use these age-depth scales as part of the basis for the dating here of six layers (spanning 30-161 ka $\mathrm{BP})$ that are linked to the Vostok ice core along the continuous RES profile between Dome A and Vostok. We then infer the spatial and temporal pattern of past accumulation rates 
(ice equivalent accumulation) at Dome A using the depthage measurements of the six isochrones.

\section{FIELD DATA}

The radar data profiles used in our study are parts of two surveys: one is part of the data collected using a dual-frequency radar system over the Dome A region by the Polar Research Institute of China (PRIC) during the 21st Chinese National Antarctic Research Expedition (CHINARE) (the black line in Fig. 1) in 2004/05; the other is the continuous RES profile of $\sim 1300 \mathrm{~km}$ length connecting the ice-core drilling sites of Vostok and Dome A, which was flown by the Alfred-Wegener-Institut (AWI) in 2007/08 as part of the Dome Connection East Antarctica (DoCo) project (the red line in Fig. 1). The PRIC survey intersects the AWI survey at two points: $S\left(80^{\circ} 21^{\prime} 27.41^{\prime \prime} \mathrm{S}, 77^{\circ} 22^{\prime} 46.54^{\prime \prime} \mathrm{E}\right)$ and $\mathrm{N}$ $\left(80^{\circ} 20^{\prime} 31.30^{\prime \prime} \mathrm{S}, 77^{\circ} 25^{\prime} 56.60^{\prime \prime} \mathrm{E}\right)$, as marked in Figure 1.

\section{MODELS}

The D-J model was used to calculate ice accumulation rates from dated radar layers in the Dome A region over the last $\sim 161 \mathrm{ka}$. The D-J model assumes a constant strain rate from the surface down to some height $z=h$ above the bed, and from there decreases linearly to zero at the base. The ice thickness $(H)$ is assumed fixed over time. The modeled age $t$ of the ice layer at depth $d=H-z$ is given by Eqn (1):

$$
t(z)=\left\{\begin{array}{cl}
\frac{2 H-h}{2 \bar{b}} \cdot \ln \left(\frac{2 H-h}{2 z-h}\right) & H \geq z \geq h \\
t(h)+\frac{2 H-h}{\bar{b}} \cdot\left(\frac{h}{z}-1\right) & h \geq z \geq 0
\end{array}\right.
$$

where $z$ and $H$ are the present and initial distance (equivalent to the ice thickness) from the bed ( $z$ is positive upwards from the bed). $\bar{b}$ is the average accumulation rate we are interested in.

The accumulation for each time slice is given by:

$$
\overline{b_{12}}=\frac{\overline{b_{2}} t_{2}-\overline{b_{1}} t_{1}}{t_{2}-t_{1}}
$$

where $\bar{b}_{1}$ and $\bar{b}_{2}$ are the average accumulations obtained by

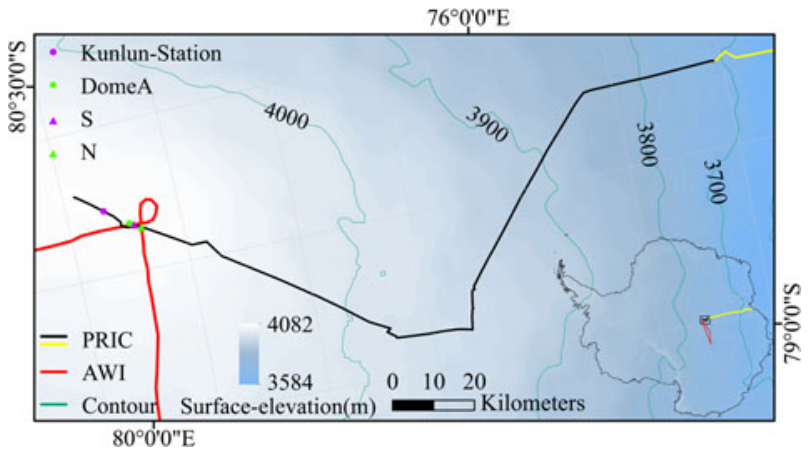

Fig. 1. The location of Kunlun Station (purple dot), Dome A (green dot), $\mathrm{S}$ (purple triangle) and $\mathrm{N}$ (green triangle), and the position of radar lines used in the analysis of internal layering. The black line shows the PRIC RES profile that is shown in Figure 2c; the yellow line shows the PRIC RES profile that is not used in our study. The red line shows the AWI RES profile that is shown in Figure 2a. Ice surface contours (green lines) are provided in $100 \mathrm{~m}$ intervals. the D-J model for layers to the depth of the respective ages $t_{1}$ and $t_{2}$.

The D-J model requires a value for $h$, which here is unknown. Different values of $h$ have been used in different applications of the D-J model. Dahl-Jensen and others (1993) determined $h$ to $1255 \mathrm{~m}$, Fahnestock and others (2001) estimated $h$ at $400 \mathrm{~m}$, Leysinger-Vieli and others (2004) took a mean value of $h=484 \mathrm{~m}$. Here, we choose the parameter $h=800 \mathrm{~m}$. We defer the details of this to the methods section.

\section{METHODS}

Internal radio-echo layering can be identified and traced across the ice sheet from analysis of radargrams. The depth of a given internal layer can be calculated from the time delay and the velocity of radio-waves. The wave velocity varies according to the state of the ice (density, temperature, fabric, etc.) at any location. Kovacs and others (1995) provide an empirical formula for radar velocity in firn of various densities taking permittivity variations of ice into consideration. An estimate of the vertical density distribution appropriate for a given site enables a 'firn correction' $Z_{\mathrm{f}}$, to be added to a preliminary calculation of the depth based on the assumption of a constant velocity appropriate for solid ice $\left(V_{\mathrm{i}}=\right.$ $168.9 \mathrm{~m} \mathrm{~ms}^{-1}$ in our study), see Appendix for details. The firn correction for PRIC data is $15 \mathrm{~m}$, which is generally applicable over the central Antarctica (Dowdeswell and Evans, 2004). The firn correction for AWI data, however, is $16.22 \mathrm{~m}$ derived from the density profiles measured at the Vostok drill site (D. Steinhage, 2015, personal communication). Hence, there is a small difference $(1.2 \mathrm{~m})$ in firn corrections for the two datasets.

Six layers can be continuously traced from Vostok along the AWI radar profile to the PRIC intersection points ( $\mathrm{S}$ and $\mathrm{N})$. Thus the depth-age scale of each layer at the location of $\mathrm{S}$ and $\mathrm{N}$ can be calculated (Fig. 2a). We traced all the clearly identifiable internal layers from PRIC radargrams, to ensure that crossover errors between these two radar lines were minimized. We calculated depth of each layer in the PRIC survey and selected the layers based on their proximity to AWI layers at the locations of S and N. The different depths of layering found in the PRIC and AWI radar surveys may be explained by considering the complex nature of the radar echo, which is a superposition of echoes from various physical impedance contrasts in the ice as well as from various points within the fresnel zone of the radar beam (Moore, 1988). This means differences in radar centre frequency, bandwidth and pulselength as well the radar hardware such as beam width, antenna focusing and receiver hardware processing of the received radar signal can all affect the appearance of layering in the final radargram. The six layers are numbered according to their age, and the depth differences of each layer between PRIC and AWI survey are shown in Figure $2 \mathrm{~b}$. Moreover, we give the range of ages for each layer with the depth error. The depth-age reference data is Vostok Ice Core Data for 420000 a (Petit and others, 1999).

Previous research shows that the appropriate value of $h$ lies between $\sim 0.2 H$ and $0.5 H$ (Cuffey and Paterson, 2011). Choosing the summit point of Dome A, $H=2200 \mathrm{~m}$ as an example, and limiting $0.2 H<h<0.5 H$, we show the effects on reconstructed accumulation rates in Figure 3. 


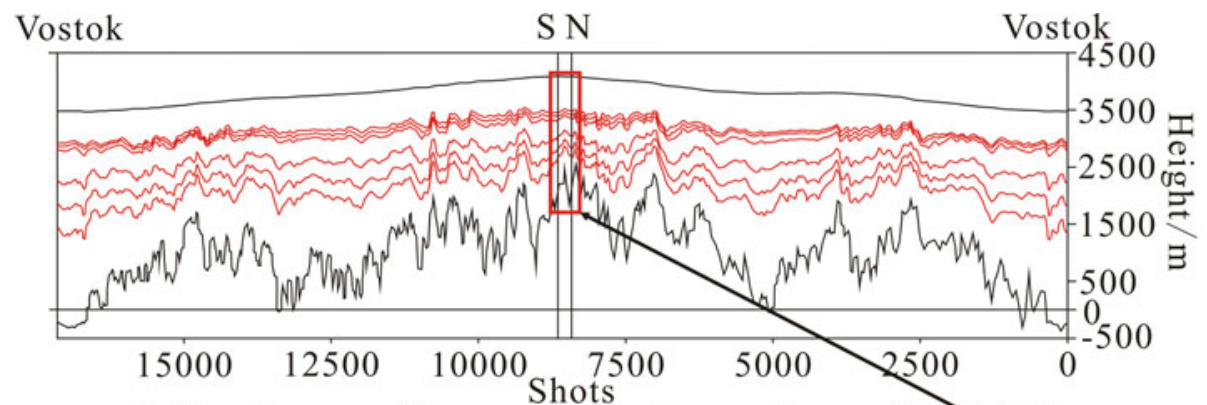

a The diagram of internal layers from radar profile or NWI

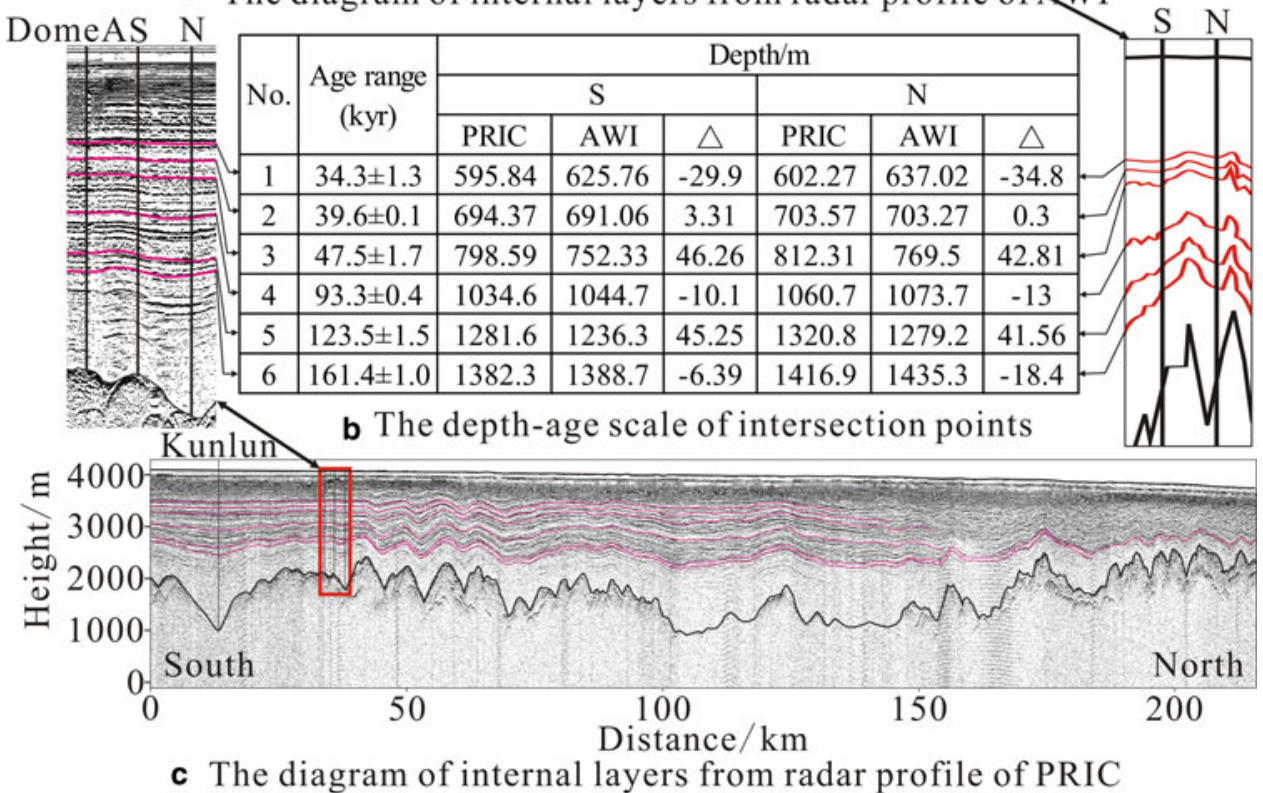

Fig. 2. Illustration of the process of dating the internal layers at Dome A region by linking them to the Vostok ice core along the RES profile. (a) Absolute depths of the internal layers from the AWI RES profile; surface and bedrock elevation are shown with black lines; the elevations of six internal layers are shown with red lines. (b) Comparison of depth for internal layers at intersection points ( $\mathrm{S} \& \mathrm{~N}$ ); six layers are numbered in Arabic numerals and given a range of ages. (c) The geometry of six internal layers is shown with magenta lines; surface and bedrock elevations are shown with black line, and overlaid on the PRIC RES radargram.

Figure 3 shows that the reconstructed accumulation rates increase gradually as $h$ is increase from 400 to $1200 \mathrm{~m}$. As $h$ increases by $100 \mathrm{~m}$, the calculated accumulation rate for six layers will increase on average by $0.19,0.28,0.35,0.45$, 0.86 and $0.99 \mathrm{~mm} \mathrm{a}^{-1}$, respectively (shown with different

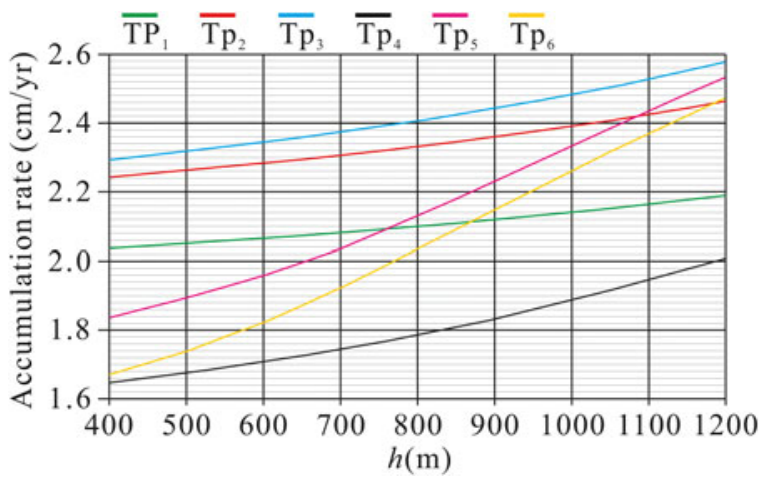

Fig. 3. Calculated accumulation rate changes with $h$. The vertical axis is for the calculated accumulation rates using Eqn (1) and the horizontal axis is for the value of $h$. TP 1 , Time Period for layer 1 $(0-34.3 \pm 1.3 \mathrm{ka} \mathrm{BP}) ; \mathrm{TP}_{2}$, Time Period for layer $2(0-39.6 \pm 0.1 \mathrm{ka}$ $\mathrm{BP}) ; \mathrm{TP}_{3}$, Time Period for layer $3(0-47.5 \pm 1.7 \mathrm{ka} \mathrm{BP}) ; \mathrm{TP}_{4}$, Time Period for layer $4(0-93.3 \pm 0.4 \mathrm{ka} B \mathrm{BP})$; $\mathrm{TP}_{5}$, Time Period for layer $5(0-123.5 \pm 1.5 \mathrm{ka} \mathrm{BP}) ; \mathrm{TP}_{6}$, Time Period for layer $6(0-161.4 \pm$ $1.0 \mathrm{ka} \mathrm{BP})$ coloured lines in Fig. 3). These variations are relatively small compared with the values of inferred accumulation rates $(0.90 \%, 1.20 \%, 1.45 \%, 2.50 \%, 4.00 \%, 4.80 \%$ percentages of the inferred accumulation rates, respectively). Thus over a reasonable range of $h$ there is minimal impact on reconstructed accumulation rates. We also find that as $h$ increases from 800 to $1200 \mathrm{~m}$, the rate of accumulation change increases, especially for the two oldest layers. Therefore a choosing $h=800 \mathrm{~m}$ is reasonable in our study given the steady-state assumptions in the D-J model.

\section{RESULTS AND DISUSSION}

\section{Spatial and temporal changes in ice accumulation}

Six layers are traced from each radargram in the Dome A region and dated by linking them to the Vostok ice core site. The ages of these isochrones from shallow to deep are $34.3 \pm 1.3, \quad 39.6 \pm 0.1,47.5 \pm 1.7,93.3 \pm 0.4,123.5 \pm 1.5$ and $161.4 \pm 1.0 \mathrm{ka}$, respectively. Using the depth-age scale data of dated layers as input with a parameter of $h=800$ $\mathrm{m}$, we reconstructed the pattern of past accumulation rates at Dome A using Eqn (1). Here, we use the reconstructed results along the radar profile with a length of $216 \mathrm{~km}$ at Dome A to analyze the spatial distribution of accumulation for each time period (Fig. 4). 


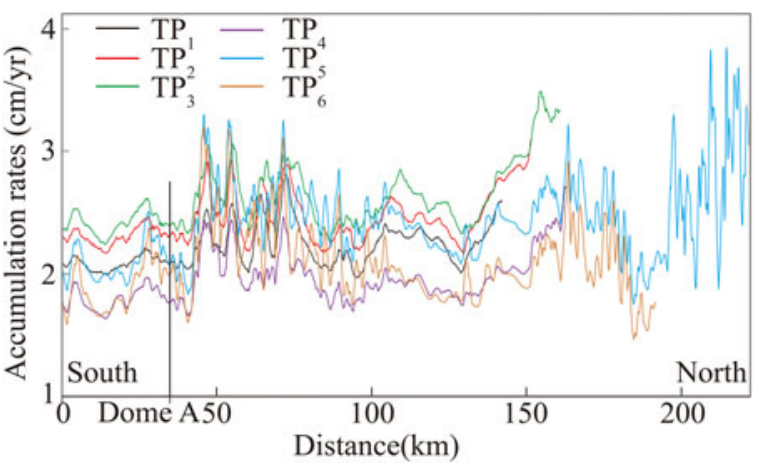

Fig. 4. Calculated accumulation rates averaged for the different time periods along the RES profile in ice equivalent. The location of Dome A is shown with black vertical line (34 $\mathrm{km}$ from the origin).

The mean accumulation rates along the transect are 2.21, 2.44, 2.62, 1.95, 2.46, $2.07 \mathrm{~cm} \mathrm{a}^{-1}$ for $\mathrm{TP}_{1}, \mathrm{TP}_{2}, \mathrm{TP}_{3}, \mathrm{TP}_{4}$, $\mathrm{TP}_{5}$ and $\mathrm{TP}_{6}$, respectively. The inferred accumulation rates vary spatially over $40-50 \mathrm{~km}$, so we smooth past accumulation rates with a $40 \mathrm{~km}$ length filter from south to north along the transect. There is an average increase of $3.6 \mathrm{~mm} \mathrm{a}^{-1}$ between the first parts $(0-40 \mathrm{~km})$ and second parts (40-80 $\mathrm{km}$ ) of the profile, and an average decrease of $2.2 \mathrm{~mm} \mathrm{a}^{-1}$ from the second part to the third part (80-120 km). Further north (130-180 km), past accumulation rates increase slightly again. However, spatial variability across the whole transect is relatively consistent over time as seen by the similarity in variability of all the layers. The relatively consistent spatial patterns at Dome A suggest that the geometry of the ice-sheet surface has not changed in gross form over the last $161 \mathrm{ka}$ (Siegert and Payne, 2004).

To investigate if the spatial pattern in ice accumulation has changed with time, we calculated the averaged accumulation rates for five different time slices along the RES profile (Fig. 5). The accumulation for each time slice is determined using Eqn (2). The mean accumulation rates are 4.20, $3.41,1.29,3.74,1.10 \mathrm{~cm} \mathrm{a}{ }^{-1}$ for $\mathrm{TP}_{12}, \mathrm{TP}_{23}, \mathrm{TP}_{34}, \mathrm{TP}_{45}$ and $\mathrm{TP}_{56}$, respectively. The conspicuous feature shown in Figure 5 is the different accumulation rates between $\mathrm{TP}_{12}$, $\mathrm{TP}_{23}, \mathrm{TP}_{45}$ and $\mathrm{TP}_{34}, \mathrm{TP}_{56}$, in which the latter two are

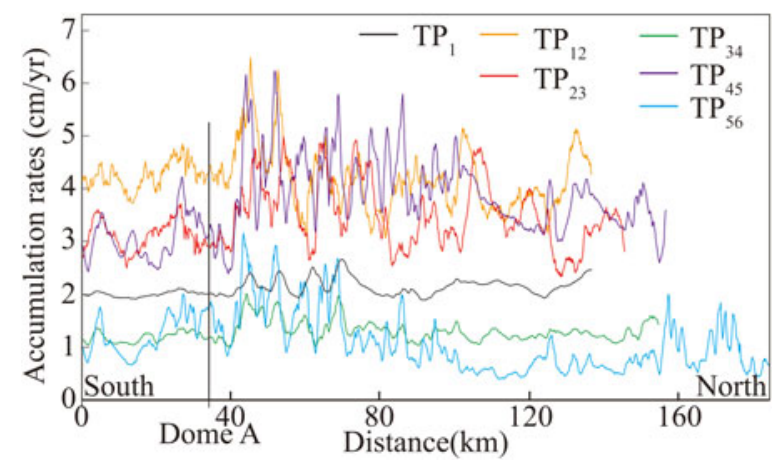

Fig. 5. Calculated accumulation rates averaged for different time slices along the RES profile in ice equivalent. The location of Dome A is shown with black vertical line ( $34 \mathrm{~km}$ from the origin). $\mathrm{TP}_{12}$, Time Period for layer $1-2$ (34.3 $\left.\pm 1.3-39.6 \pm 0.1 \mathrm{ka} \mathrm{BP}\right)$; $\mathrm{TP}_{23}$, Time Period for layer 2-3 (39.6 $\left.\pm 0.1-47.5 \pm 1.7 \mathrm{ka} \mathrm{BP}\right)$; $\mathrm{TP}_{34}$, Time Period for layer $3-4(47.5 \pm 1.7-93.3 \pm 0.4 \mathrm{ka} B P)$; $\mathrm{TP}_{45}$, Time Period for layer $4-5$ (93.3 $\left.\pm 0.4-123.5 \pm 1.5 \mathrm{ka} \mathrm{BP}\right)$; $\mathrm{TP}_{56}$, Time Period for layer 5-6 (123.5 $\left.\pm 1.5-161.4 \pm 1.0 \mathrm{ka} \mathrm{BP}\right)$. lower than former three. Calculated results for $\mathrm{TP}_{12}, \mathrm{TP}_{23}$ and $\mathrm{TP}_{34}$ show how the accumulation changed through time since the last glacial period (13-116 ka ago). From the comparison of mean accumulation rates between $\mathrm{TP}_{2}, \mathrm{TP}_{3}$ and $\mathrm{TP}_{12}, \mathrm{TP}_{23}$, it is clear that the latter two are larger than the former, indicating that there were relatively high accumulation rates at Dome A for the time period of 34-47 ka ago. We compare our results to Lorius and others (1985), a study that derived a $150 \mathrm{ka}$ climatic record from Vostok ice core. The successive warm and cold stages are designated by letters A-H consecutively from the top of the record downwards in Figure 6. As can be seen in the Figure 6, stage C (30-58 ka ago), which is roughly equivalent to Marine Isotope Stage 3 (MIS3: 29-59 ka ago), was a relatively warm interstadial, an intermediate stage between full glacial and interglacial conditions, which may explain why Dome A experienced relatively high accumulation for the time period $\sim 34-47 \mathrm{ka}$. While temperature might play a role in accumulation rates, it might not be the only story since the most recent warm interval does not appear to have high accumulation rates.

\section{Comparison with previous studies of Dome A}

There are several studies on present-day accumulation rates at Dome A. Hou and others (2007) calculated recent accumulation rates at Dome $A$ as $2.3 \mathrm{~cm}$ w.e. $\mathrm{a}^{-1}$ based on the $\beta$ radioactivity horizon and the density profile. Ding and others (2011) studied the overall spatial characteristics of the surface mass balance $(\mathrm{SMB})$ using stake measurements along a traverse route that starts at Zhongshan and ends at the Dome A summit. They find that the Dome A zone has the lowest snow accumulation rate $\left(3.5 \mathrm{~cm} \mathrm{a}^{-1}, 2005-08\right)$. Wang and others (2013) inferred the spatial and temporal variability of snow accumulation near Dome A from snow pit and stake measurement data. The results suggest that the snow accumulation rate shows large interannual variations, but stable multi-decadal averages over the last 7 centuries. The calculated past accumulation rates at Dome $A$ in our study are within a factor of 2 of these recent accumulation rates, although the lowest past accumulation rate for layer 4 was below $2 \mathrm{~cm} \mathrm{a}^{-1}$. Accumulation rate variability between glacial and interglacial periods varied by a factor of 2 in the Vostok ice core (Lorius and others, 1985).

Studies about past accumulation rate at Dome $\mathrm{A}$ are nearly absent. Siegert (2003) calculated the mean accumulation rates $\left(1.6 \mathrm{~cm} \mathrm{a}^{-1}\right.$, Fig. 6 red dashed line) for the past 94 ka along a radar line $\sim 100 \mathrm{~km}$ from the summit of Dome A, which suggests an accumulation rate $\sim 0.27 \mathrm{~cm} \mathrm{a}^{-1}$ lower than the result in our study $\left(1.87 \mathrm{~cm} \mathrm{a}^{-1}\right.$ for $\mathrm{TP}_{4}$. Figure 6 red solid line). They also inferred accumulation rates using radar layer depths along a radar line of length $200 \mathrm{~km}$ that crossed over Ridge B and Vostok station (the corresponding results are indicated in Fig. 6 by the blue solid line). The study used a layer of a similar age $(45.9 \mathrm{ka})$ and time period (45.9-83.5 ka) to layer 3 and $\mathrm{TP}_{34}$ in our study, respectively. These results suggest that the mean accumulation rate along the transect in our study is $0.38 \mathrm{~cm} \mathrm{a}^{-1}$ more than the average rate over the transect between Ridge $B$ and Vostok for the last $\sim 46 \mathrm{ka}$. The rate of ice accumulation in our study $\left(1.28 \mathrm{~cm} \mathrm{a}^{-1}\right.$ at Dome $\mathrm{A}$ zone), however, is lower than that in Siegert's study for the time period $\sim 46-$ $90 \mathrm{ka}\left(1.50 \mathrm{~cm} \mathrm{a}^{-1}\right)$. Both Siegert's and our study show a 


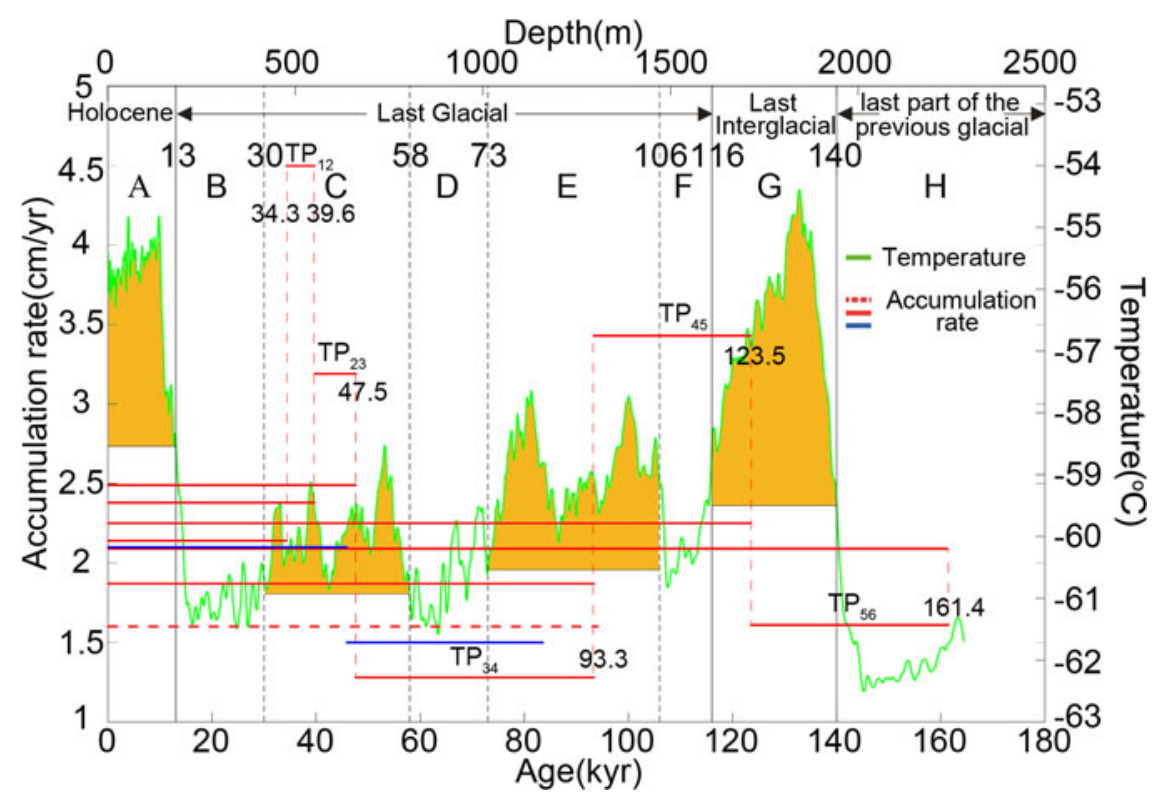

Fig. 6. Surface temperatures (green line) versus depth inferred for Vostok with the definition of the successive stages and indication of the ages corresponding to the limits between these stages (Lorius and others, 1985). Stage A (0-13 ka) corresponds to the present Holocene period; Stages B-F (13-116 ka) cover the last glacial; Stage G (116-140 ka) includes the peak of the last interglacial and stage H (before $140 \mathrm{ka})$ is the last part of the previous glacial. The warm periods (filled areas) are designated by A, C, E, G and the cold periods by B, D, F, $\mathrm{H}$. Calculated accumulation rates for different time periods at Dome A in our study are shown with red solid lines; the red dashed line corresponds to the mean accumulation rates, for the past $94 \mathrm{ka}$, across a radar line $100 \mathrm{~km}$ from the summit of Dome A (Siegert, 2003); the blue lines corresponds to the averaged accumulation rates across Vostok-Ridge B transect for the past 45.9 ka and between 45.9 and 83.5 ka (Siegert, 2003).

similar temporal pattern that the accumulation rates for the past $\sim 60$ ka are higher than that for $\sim 46-90 \mathrm{ka}$ ago.

\section{Discussion}

The D-J model is a simple one-dimensional flow model and by using it to calculate the accumulation rate, we minimize the effect of the horizontal flow. The use of D-J model is most appropriate near an ice divide, where slow or negligible horizontal flow means that all the ice at depth originates from near the same location on the surface. The horizontal surface velocity values are close to zero at the summit of Dome A $\left(11.1 \pm 2.4 \mathrm{~cm} \mathrm{a}^{-1} ;\right.$ Yang and others, 2014) and increases with distance from the summit. The horizontal velocity increases from $1.3 \mathrm{~m} \mathrm{a}^{-1}$ at site of $150 \mathrm{~km}$ distance from the summit of Dome A to $3.0 \mathrm{~m} \mathrm{a}^{-1}$ at site of $230 \mathrm{~km}$ distance from the summit of Dome A (Zhang and others, 2008). Macgregor and others (2009) infer accumulation rates from three radar layers $(26,35$ and $41 \mathrm{ka}$ old) in the Vostok Subglacial Lake region using two methods: one is the same as the method used in our study and the other is a combination of steady-state flowband modeling (model inputs include ice-surface elevations, ice velocities and temperatures) and formal inverse methods. By comparing the results of two methods, for all three layers along one flowband, which crosses the Vostok station (surface-velocity is $\sim 2 \mathrm{~m} \mathrm{a}^{-1}$ ), the mean difference between two results is $4 \%$, which is a relatively small considering other uncertainties in the method. Sun and others (2014) calculate the basal temperatures around Dome A; for a geothermal heat flux of 50 $\mathrm{mWm}^{-2}$, only a small fraction of the basal ice in the $30 \times$ $30 \mathrm{~km}^{2}$ domain centered around Kunlun station is at the pressure melting point. Consequently, we do not expect the absence of horizontal shear strain and basal melt in the D-J model to affect the results of spatial and temporal pattern of accumulation rate at Dome $\mathrm{A}$ in our study. However heat flux is largely unknown in the region, and larger areas of the bed are at pressure-melting point for higher heat fluxes.

Bell and others (2011) showed that around Dome A, 24\% of the area contains frozen-on ice features, which drive substantial mass redistribution from localized basal melt and subsequent re-freezing at the bottom of the ice sheet. These features clearly show that regions of the basal ice must be at pressure-melting point. A freeze-on ice structure was also found in the PRIC RES profile along the traverse from Zhongshan station to Kunlun station (Tang and others, 2015) located 1044-1056 km from the coast. No freeze-on ice structures were however found within the transect in our study. Sun and others (2014) also showed the importance of the ice fabric in determining the ice vertical velocity, and hence the age of layers with depth. This effect is not included in the D-J model, however, the effects of fabric are typically significant only much closer to the base of the ice than in the relatively shallow ice containing the 6 RES isochrones analyzed here.

Waddington and others (2007) defined a non-dimensional depth number $D$, to express the relationship between the horizontal distance that a particle has traveled from the surface to any layer, and the characteristic length scales of accumulation-rate and ice-thickness variability. The equation for calculating $D$ is defined as follows:

$$
D=(\bar{U} \times \mathcal{A}) \times\left(\frac{1}{L_{\dot{b}}}+\frac{1}{L_{H}}\right)
$$

where $\bar{U}$ is the temporally averaged horizontal velocity of a particle as it following a particle path, $\mathcal{A}$ is the age of the layer. $1 / L_{\dot{b}}=|(1 / \dot{b})(\mathrm{d} \dot{b} / \mathrm{d} x)|$ and $L_{\dot{b}}$ is the length over 
which $\dot{b}$ changes by an appreciable fraction; Similarly, $1 / L_{H}=|(1 / H)(\mathrm{d} H / \mathrm{d} x)|$ and $L_{H}$ is the length over which ice thickness changes by an appreciable fraction.

If $D \ll 1$ the spatial gradients in accumulation rates and ice thickness do not significantly affect the layer depths, and hence the D-J model is sufficiently accurate to infer accumulation rates. The values of $D$ for the upper four layers in our study are both $<0.09$, and the $D$ values of the other two layers are $\sim 0.1$. This suggests that even the deepest and oldest layers studied here are not significantly affected by spatial variability in accumulation and that the D-J model is acceptable to infer these accumulation rates at Dome A region.

\section{CONCLUSIONS}

Depth-age relationships are extended from Vostok ice core to Dome A. Six dated radar isochrones layers are traced from a radar profile collected in the Dome A region. The D-J model, using the depth-age measurements as input, is then used to infer the spatial and temporal variations in Dome A accumulation rates. The main result of this investigation is a generalized view of the spatial and temporal variation in ice accumulation over the last $\sim 161 \mathrm{ka}$.

The lowest average ice accumulation rates for each time window were calculated at Dome A (smoothed over $40 \mathrm{~km})$, which are 2.09, 2.30, 2.41, 1.79, 2.21 and 1.88 $\mathrm{cm} \mathrm{a}{ }^{-1}$ for $\mathrm{TP}_{1}, \mathrm{TP}_{2}, \mathrm{TP}_{3}, \mathrm{TP}_{4}, \mathrm{TP}_{5}$ and $\mathrm{TP}_{6}$, respectively. The spatial variability shows an increase or decrease of $0.7-4.0 \mathrm{~mm} \mathrm{a}^{-1}$ on a scale of $40 \mathrm{~km}$ (Fig. 4). As a whole, ice-accumulation rates increase slightly from south to north along the radar profile over a distance of $216 \mathrm{~km}$, starting from the summit of Dome $A$.

At Dome $A$, the mean accumulation for $\mathrm{TP}_{2}$ and $\mathrm{TP}_{3}$ is higher than that for $\mathrm{TP}_{1}$ and $\mathrm{TP}_{4}$, which suggests that Dome A experienced relatively high accumulation 34-47 ka ago, roughly corresponding to the warm interstadial Marine Isotope Stage 3. The variability of accumulation rates is almost a factor of 4 on scales of tens of ka (see Fig. $5, \mathrm{TP}_{12}$ and $\left.\mathrm{TP}_{56}\right)$. This is probably more than would be expected from climatically driven changes in accumulation rates. This suggests that other factors such as the steady-state assumptions in the modeling may be questioned. However, despite complicating factors known to exist in ice around Dome A, such as basal accumulation of ice and varying ice fabric with depth, tests on the suitability of the simple $1 \mathrm{di}$ mensional flow modeling method for the relatively shallow radar isochrones suggest that it can provide reasonable estimates of accumulation rate variability over the past $160 \mathrm{ka}$.

This paper is a first attempt to calculate past accumulation rates for Dome A, East Antarctica. A sophisticated 3-D flow model for the Dome $\mathrm{A}$ region has already been developed (Sun and others, 2014), and with advances in basal hydrology incorporated within it, a more accurate and longer time series of past accumulation rates at Dome $A$ will be derived. This work can also be independently verified with data from the Dome A deep ice core in the near future.

\section{ACKNOWLEDGEMENTS}

Work was supported by China's National Key Science Program (2012CB957702, 2013CBA01804), the National High-tech R\&D Program of China (2011AA040202) and the Chinese Polar Environmental Comprehensive
Investigation and Assessment Programs (CHINARE-02-02), Foreign Cooperation Support of Chinese Arctic and Antarctic Administration, SOA, China (IC201214), National Science Foundation of Shanghai, China (13ZR1445300), National Natural Science Foundation of China (41376192).

\section{REFERENCES}

Arthern RJ, Winebrenner DP and Vaughan DG (2006) Antarctic snow accumulation mapped using polarization of 4.3-cm wavelength microwave emission. J. Geophys. Res., 111, D06107 (doi: 10.1029/2004JD005667)

Bell RE and 11 others (2011) Widespread persistent thickening of the East Antarctic ice sheet by freezing from the base. Science $\mathbf{3 3 1}$ (6024), 1592-1595 (doi: 10.1126/science.1200109)

Corr H, Moore JC and Nicholls KW (1993) Radar absorption due to impurities in Antarctic ice. Geophys. Res. Lett., 20(11), 10711074 (doi: 10.1029/93gl01395)

Cuffey KM and Paterson WSB (2011) The physics of glaciers, 4th edn. Butterworth-Heinemann Publications (Elsevier), USA, 611-674 (ISBN: 978-0-12-369461-4)

Dahl-Jensen D, Johnsen SJ, Hammer CU, Clausen HB and Jouzel J (1993) Past accumulation rates derived from observed annual layers in the GRIP ice core from summit, Central Greenland. Ice Clim. Syst., I-12, 517-532 (doi: 10.1007/978-3-642-850165_29)

Dansgaard W and Johnsen SJ (1969) A flow model and a time scale for the ice core from Camp Century, Greenland. J. Glaciol., 8(53), 215-223

Ding $\mathrm{MH}$ and 6 others (2011) Spatial variability of surface mass balance along a traverse route from Zhongshan station to Dome A, Antarctica. J. Galciol., 57(204), 658-666 (doi: 10.3189/002214311797409820)

Dowdeswell JA and Evans S (2004) Investigations of the form and flow of ice sheet and glaciers using radio-echo sounding. Rep. Prog. Phys., 67, 1821-1861 (doi: 10.1088/0034-4885/67/10/ R03)

Fahnestock M, Abdalati W, Luo S and Gogineni S (2001) Internal layer tracing and age-depth-accumulation relationships for the northern Greenland ice sheet. J. Geophys. Res., 106(D24), 33,789-33,797 (doi: 10.1029/2001JD900200)

Fujita $S$ and 6 others (1999) Nature of radio echo layering in the Antarctic ice sheet detected by a two-frequency experiment. J. Geophys. Res., 104(B6), 13,013-13,024 (doi: 10.1029/1999 JB900034)

Hindmarsh RCA, Leysinger-Vieli GJ-MC and Parrenin F (2009) A large-scale numerical model for computing isochrones geometry. Ann. Glaciol., 50(51), 130-140 (doi: 10.3189/ 172756409789097450)

Hou SG, Li YS, Xiao CD and Ren JW (2007) Recent accumulation rate at Dome A, Antarctica. Chin. Sci. Bull., 52(3), 428-431 (doi: 10.1007/s11434-007-00413)

Huybrechts P, Rybak O, Steinhage D and Pattyn F (2009) Past and present accumulation rate reconstruction along the Dome FujiKohnen radio-echo sounding profile, Dronning Maud Land, East Antarctica. Ann. Glaciol., 50(51), 112-120 (doi: 10.3189/ 172756409789097513)

Kovacs A, Gow AJ and Morey RM (1995) The in-situ dielectric constant of polar firn revisited. Cold Reg. Sci. Technol., 23, 245-256 (doi: 10.1016/0165-232x(94)00016-q)

Lenaerts JTM, van den Broeke MR, van de Berg WJ, van Meijgaard E and Munneke PK (2012) A new, high-resolution surface mass balance map of Antarctica (1979-2010) based on regional atmospheric climate modeling. Geophys. Res. Lett., 39, L04501 (doi: 10.1029/2011GL050713)

Leysinger-Vieli GJ-MC, Siegert MJ and Payne AJ (2004) Reconstructing ice-sheet accumulation rates at Ridge B, East Antarctica. Ann. Glaciol., 39, 326-330 (doi: 10.89/ 172756404781814519) 
Leysinger-Vieli GJ-MC, Hindmarsh RCA, Siegert MJ and Sun B (2011) Time-dependence of the spatial pattern of accumulation rate in East Antarctica deduced from isochronic radar layers using a 3-D numerical ice flow model. J. Geophys. Res., 116, F02018 (doi: 10.1029/2010JF001785)

Lorius C and 6 others (1985) A 150,000-year climatic record from Antarctic ice. Nature, 316, 591-596 (doi: 10.1038/316591a0)

Macgregor JA and 5 others (2009) Millennially averaged accumulation rates for the Vostok Subglacial Lake region inferred from deep internal layers. Ann. Glaciol., 50(51), 25-34 (doi: 10.3189/172756409789097441)

Millar DHM (1981) Radio-echo layering in polar ice sheets and past volcanic activity. Nature, 292, 441-443 (doi: 10.1038/ 292441a0)

Moore JC (1988) Dielectric variability of a $130 \mathrm{~m}$ Antarctic ice core: implications for radar sounding. Ann. Glaciol., 11, 95-99

Nereson NA, Raymond CF, Jacobel RW and Waddington ED (2000) The accumulation pattern across Siple Dome, West Antarctica, inferred from radar-detected internal layers. J. Glaciol., 46(152), 75-87 (doi: 10.3189/172756500781833449)

Oerter $\mathrm{H}$ and 6 others (2000) Accumulation rates in Dronning Maud Land, Antarctica, as revealed by dielectric-profiling measurements of shallow firn cores. Ann. Glaciol., 30, 27-34 (doi: 10.3189/172756400781820705)

Paren JG and Robin GdeQ (1975) Internal reflections in polar ice sheets. J. Galciol., 14(71), 251-259

Petit JR and 18 others (1999) Climate and atmospheric history of the past 420,000 years from the Vostok ice core, Antarctica. Nature, 399, 429-436 (doi: 10.1038/20859)

Robin GdeQ, Evans S and Bailey JT (1969) Interpretation of radio echo sounding in polar ice sheets. Phil. Trans. R. Soc. London Ser. A, 265(116), 437-505 (doi: 10.1098/rsta.1969.0063)

Siegert MJ (2003) Glacial-interglacial variations in central East Antarctic ice accumulation rates. Quat. Sci. Rev., 22, 741-750 (doi: 10.1016/s0277-3791(02)00191-9)

Siegert MJ and Payne AJ (2004) Past rates of accumulation in central West Antarctica. Geophys. Res. Lett., 31, L12403 (doi: 10.1029/ 2004GL020290)

Sun B and 8 others (2009) The Gamburtsev Mountains and the origin and early evolution of the Antarctic ice sheet. Nature, 459, 690693 (doi: 10.1038/nature08024)

Sun B and 8 others (2014) How old is the ice beneath Dome A, Antarctica? Cryosphere, 8(3), 1121-1128 (doi: 10.5194/tc-81121-2014)

Tang XY and 6 others (2015) A freeze-on ice zone along the Zhongshan-Kunlun station ice sheet profile, East Antarctica, by a new ground-based ice-penetrating radar. Sci. Bull., 60(5), 574-576 (doi: 10.1007/s11434-015-0732-0)

Waddington ED, Neumann TA, Koutnik MR, Marshall HP and Morse DL (2007) Inference of accumulation-rate patterns from deep layers in glaciers and ice sheets. J. Glaciol., 53(183), 694712 (doi: 10.3189/002214307784409351)

Wang YT and 5 others (2013) Snow accumulation and its moisture origin over Dome Argus, Antarctica. Clim. Dyn., 40(3), 731-742 (doi: 10.1007/s00382-012-1398-9)

Xiao CD and 5 others (2008) Preliminary evidences indicate Dome A (Antarctica) satisfying preconditions for drilling the oldest ice core. Chin. Sci. Bull., 53(1), 102-106 (doi: 10.1007/s11434-0070520-6)

Yang YD and 8 others (2014) GPS-derived velocity and strain fields around Dome Argus, Antarctica. J. Glaciol., 20(222), 735-742 (doi: 10.3189/2014JoG14J078)
Zhang $N$ and 9 others (2014) Chinese first deep ice-core drilling project DK-1 at Dome A, Antarctica (2011-2013): progress and performance. Ann. Glaciol., 55(68), 88-98 (doi: 10.3189/ 2014AoG68A006)

Zhang SK and 5 others (2008) Ice velocity from static GPS observations along the transect from Zhongshan station to Dome A, East Antarctica. Ann. Glaciol., 48(1), 113-118 (doi: 10.3189/ 172756408784700716)

\section{APPENDIX FIRN CORRECTION}

Since the conductivity of dry polar firn and ice is extremely low, the effective phase velocity of high-frequency electromagnetic waves can be determined from

$$
V_{\mathrm{e}}=\frac{\mathrm{C}}{\boldsymbol{\epsilon}_{\mathrm{e}}^{\prime}}
$$

where $c$ is the velocity of an electromagnetic wave in a vacuum, $0.3 \mathrm{~m} \mathrm{~ns}^{-1} \cdot \epsilon_{\mathrm{e}}^{\prime}$ is the relative effective dielectric constant.

Kovacs and others (1995) combined published field data for electromagnetic wave velocities in polar firn. They found that an empirical linear relationship between the refractive index $n$ and density $\rho$, that had been developed much earlier (Robin and others, 1969), produced the best statistical fit:

$$
n=1+K \rho
$$

since $n^{2}=\epsilon_{\mathrm{e}}^{\prime}$ in the radio-radar frequency range of interest, then

$$
\epsilon_{\mathrm{e}}^{\prime}=(1+K \rho)^{2}
$$

Robin and others (1969) adopted the coefficient $K=0.851 \times$ $10^{-3} \mathrm{~m}^{3} \mathrm{~kg}^{-1}$, and Kovacs and others (1995) made a small adjustment to the coefficient $K, K=0.845 \times 10^{-3} \mathrm{~m}^{3} \mathrm{~kg}^{-1}$.

An estimate of the vertical density distribution appropriate for a given site enables a correction (firn correction $z_{\mathrm{f}}$ ) that will be added to a preliminary calculation of the depth based on the assumption of a constant velocity appropriate for solid ice (Dowdeswell and others, 2004).

$$
\begin{aligned}
& z_{\mathrm{f}}=\lim _{t \rightarrow 0} \sum_{j=1}^{n}\left(\frac{t C}{2 \sqrt{\epsilon_{\mathrm{fj}}}}-\frac{t C}{2 \sqrt{\epsilon_{\mathrm{i}}}}\right) \\
& \Rightarrow z_{\mathrm{f}}=\lim _{t \rightarrow 0} \sum_{j=1}^{n} \frac{t c K}{2 n_{\mathrm{i}} n_{\mathrm{fj}}}\left(\rho_{\mathrm{i}}-\rho_{\mathrm{fj}}\right) \\
& \Rightarrow z_{\mathrm{f}}=\frac{K}{n_{\mathrm{i}}} \int\left(\rho_{\mathrm{i}}-\rho_{\mathrm{z}}\right) \mathrm{d} z
\end{aligned}
$$

where $t$ is the two-way vertical travel time, $\mathrm{i}-$ ice, $\mathrm{f}-$ firn. Here the density of solid ice is $\rho_{\mathrm{i}}=917 \mathrm{~kg} \mathrm{~m}^{-3}$. Kovacs and others adopted a value of $\epsilon_{\mathrm{i}}=n_{\mathrm{i}}^{2}=3.15$ for solid ice. 